\title{
Simonkolleite Nano-platelets: Synthesis and Temperature effect on Hydrogen Gas Sensing Properties
}

\author{
J. Sithole ${ }^{1,2}$, B D Ngom ${ }^{1,3,4}$, S. Khamlich ${ }^{1,3}$, E. Manikanadan ${ }^{5}$, N. Manyala ${ }^{6}$, M.L. \\ Saboungi ${ }^{7}$, D. Knoessen ${ }^{2}$, R. Nemutudi ${ }^{1}$, and M. Maaza ${ }^{1}$ \\ 1 NANOAFNET, MRD-iThemba LABS, National Research Foundation,1 Old Faure road, Somerset \\ West 7129, South Africa \\ 2 Dept. of Physics, University of Western Cape, Private Bag X 17, Belleville, South Africa. \\ ${ }^{3}$ African Laser Centre, CSIR campus, P.O. Box 395, Pretoria, South Africa \\ ${ }^{4}$ Laboratoire de Photonique et de Nano-Fabrication, Groupe de Physique du Solide et Sciences des \\ Matériaux, Département de Physique Facultés des Sciences et Technique Université Cheikh Anta \\ Diop de Dakar, Dakar, Sénégal \\ ${ }^{5}$ National Centre for Nano-Structured Materials (NCNSM), Council for Scientific and Industrial \\ Research, Pretoria, South Africa \\ ${ }^{6}$ Department of Physics, SARCHI Chair in Carbon Technology and Materials, Institute of \\ Applied Materials, University of Pretoria, Pretoria 0028, South Africa \\ ${ }^{7}$ Centre de Recherche sur la Matière Divisée, CNRS-Orléans, Orléans, France
}

Keywords: Nano-Particles, Zinc Oxide, Simonkolleite, Hydrothermal, photonics and Gas sensing,

\begin{abstract}
In this work, the new refined mineral platelets-like morphology of simonkolleite based particles described by Shemetzer et al. (1985) were synthesized in zinc nitrate aqueous solution by a moderate solution process. The morphological and structural properties of the platelets-like $\mathrm{Zn}_{5}(\mathrm{OH})_{8} \mathrm{Cl}_{2} \cdot \mathrm{H}_{2} \mathrm{O}$ were characterized by scanning electron microscope energy dispersed X-ray spectroscopy, transmission electron microscope, powder X-ray diffraction and selected area electron diffraction as well as attenuated total reflection infrared spectroscopy. The morphology as well as the size in both basal and transversal directions of the simonkolleite $\mathrm{Zn}_{5}(\mathrm{OH})_{8} \mathrm{Cl}_{2} \cdot \mathrm{H}_{2} \mathrm{O}$ nano/micro crystals was found to be significantly depending on the specific concentration of $0.1 \mathrm{M}$ of $\mathrm{Zn}^{2+} / \mathrm{Cl}^{-}$ions in the precursor solution. The simonkolleite $\mathrm{Zn}_{5}(\mathrm{OH})_{8} \mathrm{Cl}_{2} \cdot \mathrm{H}_{2} \mathrm{O}$ nano-platelets revealed a significant and singular $\mathrm{H}_{2}$ gas sensing characteristics. The operating temperature was found to play a key role on the sensing properties of simonkolleite. The effect of temperature on the simonkolleite sample as a hydrogen gas sensor was studied by recording the change in resistivity of the film in presence of the test gas. The results on the sensitivity and response time as per comparison to earlier reported ZnO based sensors are indicated and discussed.
\end{abstract}




\section{Introduction}

$\mathrm{Zn}_{5}(\mathrm{OH})_{8} \mathrm{Cl}_{2} \cdot \mathrm{H}_{2} \mathrm{O}$ was first described and named by Schmetzer et al. [1]. It occurs as a natural weathering product of $\mathrm{Zn}$-bearing mine slags in the German region of Richelsdorf. More precisely, Schmetzer et al. (1985) identified wulfingite $\left(\mathrm{Zn}(\mathrm{OH})_{2}\right)$, along with native $\mathrm{Zn}$, zincite and hydrozincite. It was named after Werner Simon and Kurt Kolle, the mineral collectors of Cornberg near Michelsdorf in Germany, who were the first to submit the corresponding samples for investigation [1]. Most reports on simonkolleite are geared towards bulk properties with a net focus on understanding the surface atmospheric corrosion products on Zn plates [2]. While colorless, simonkolleite forms tabular hexagonal crystals up to $\sim 1 \mathrm{~mm}$ in diameter, and has perfect cleavage parallel to the (001) direction. It is a soft compound with a Mohs hardness of $\sim 1.5$ and a specific gravity of 3.2. The crystal structure of the synthesis analogue of simomkolleite was reported by Nowacki et al [3] and Allmann [4].

The oxygen vacancies on the surface of simonkolleite are electrically and chemically active, as in the case of $\mathrm{ZnO}$. These vacancies may then function as n-type donors and thus significantly increase the material's conductivity. According to the gas sensing mechanism, normally accepted for semiconductor gas sensor, the oxygens adsorbed on the surface of the oxide may assumingly remove charges and thus decreases the material's conductivity.

Common sensors proposed to use an indirect approach (e.g. Raman spectroscopy, etc.) or requiring complicated components to detect the presence of $\mathrm{H}_{2}$. Many ideas have been proposed such as use of different metal wires [5], semiconductor oxides nanoarchitectures [6], etc. Gas sensors based on $\mathrm{ZnO}$ nanorods, $\mathrm{SnO}_{2}$ nanowires, $\mathrm{In}_{2} \mathrm{O}_{3}$ nanowires, etc. showed excellent response and recover characteristics [7] and can potentially overcome obstacles of other type of sensors, such as sensitivity, selectivity, etc. One of the requirements of the gas sensors is low power consumption, because the sensors need to work reliably and continuously. A low resistance material has lower driving power when it is used as a sensor. Appropriate donor doping can produce the electronic defects that increase the influence of oxygen partial pressure on the conductivity. Nanto et al. [8] showed that a lower operating temperature may be achieved by the doping effect, and a significant resistance change can be obtained in the doped $\mathrm{ZnO}$ rather than the undoped $\mathrm{ZnO}$ sensor, which results in a higher sensitivity [8]. Especially for the application of $\mathrm{ZnO}$ as gas sensors porous microstructure of the materials with controlled pore size is preferred. The sensitivity and response time of ZnO based sensors strongly depend on the porosity of the material [9]. 
Hydrogen and fuel-cell technologies are believed to be the energy solutions for the twenty-first century, enabling clean, efficient production of power and heat from a range of primary energy sources. In the spectrum of technologies that interconnect to shape the global hydrogen economy vision, platinum plays a crucial role as a catalyst that converts hydrogen to electricity. According to the International Platinum Association (2003), no other material has been shown to be as effective as platinum in protonexchange-membrane fuel cells (PEMFCs). The transition to a future "hydrogen economy" is expected to reduce dependency on oil and gas greatly, and reduce carbon dioxide emissions. However, $\mathrm{H}_{2}$ is a hazardous, odourless and highly inflammable gas and it is necessary to detect its leakage. A reliable and inexpensive sensor that can take advantage of nanoscale to detect hydrogen leaks is the focus of many research groups $[1-4,10,11]$.

In terms of synthesis of simonkolleite, zinc chloride was used as a precursor so far for bulk synthesis [6]. In addition of the nano-scaled aspect, and using zinc nitrate along with sodium chloride aqueous solution as a starting material was seldom reported, if any. Hence, the present contribution reports on for the first time relatively low temperature synthesis of nano and micron scaled simonkolleite with a pronounced shape anisotropy; platelets-like hexagonal nano/micro crystals and its initial $\mathrm{H}_{2}$ gas sensing investigations.

\section{Experimental details}

A solution containing zinc nitrate hexahydrate $\left(\mathrm{Zn}\left(\mathrm{NO}_{3}\right)_{2} \cdot 6 \mathrm{H}_{2} \mathrm{O}\right)$, sodium chloride $(\mathrm{NaCl})$ and hexamethylenetetramine $\left(\mathrm{C}_{6} \mathrm{H}_{12} \mathrm{~N}_{4}, \mathrm{HMT}\right)$ was used for deposition of simonkolleite plate-like structures. A bottle $100 \mathrm{ml}$ with autoclavable screw cap was filled with an equimolar $\left(10^{-1} \mathrm{M}\right)$ aqueous solution of $\mathrm{Zn}\left(\mathrm{NO}_{3}\right)_{2} \cdot 6 \mathrm{H}_{2} \mathrm{O}$, $\mathrm{HMT}$ and $\mathrm{NaCl}$. The reaction solution was about $100 \mathrm{ml}$. Subsequently a piece of cleansed glass substrate, with alcohol and deionised water, was immersed in the solution and heated at a constant temperature at $85^{\circ} \mathrm{C}$. Various deposition times of about $2.4,8$, and $24 \mathrm{~h}$ in a regular laboratory oven were used, respectively. Finally, the thin film was thoroughly rinsed with deionized water to eliminate residual salts, and dried in air at the same temperature used in the oven. Scanning electron microscopy "SEM, Jeol 3000", and powder X-ray diffraction (XRD), with $\mathrm{CuK}_{\mathrm{a} 1}$ radiation (D8 advance Bruker X-ray diffractometer, $\lambda=0.154060 \mathrm{~nm}$ at $40 \mathrm{kV}$ and $40 \mathrm{~mA}$ ), were used to investigate the surface morphology and structural properties of $\mathrm{ZnO}$, respectively. Furthermore; infrared attenuated total reflection spectrophotometry was used to confirm the simonkoleitte phase structure. The gas sensing sensors based on simonkolleite nano-micro platelets were fabricated. The gas sensor was put in a cylindrical gas flow chamber with $10 \mathrm{~cm}$ in diameter, $15 \mathrm{~cm}$ in 
height fabricated with $\mathrm{Cu}$ plates electrodes at each end of the tube with a coil heater inserted into the tube. The gas sensor was put in a cylindrical gas flow chamber and allows the concentration of $200 \mathrm{ppm}$ hydrogen gas with work temperatures from $150^{\circ} \mathrm{C}$ to $350{ }^{\circ} \mathrm{C}$ to pass through the chamber. The $\mathrm{H}_{2}$ gas sensing properties were recorded using a computer controlled gas sensing characterization system. The relative concentration of the $\mathrm{H}_{2}$ gas was measured using pre calibrated gas flow meters. The change in film resistance was noted in the same concentration of the test gas at several temperatures. The sensitivity $\left[\left(R_{\text {air }}-R_{\text {gas }}\right) / R_{\text {air }}\right]$ defined as the percentage change of the film resistance in presence of the test gas was calculated for each temperature. The sensor response and recovery times were determined from the transient response characteristics.
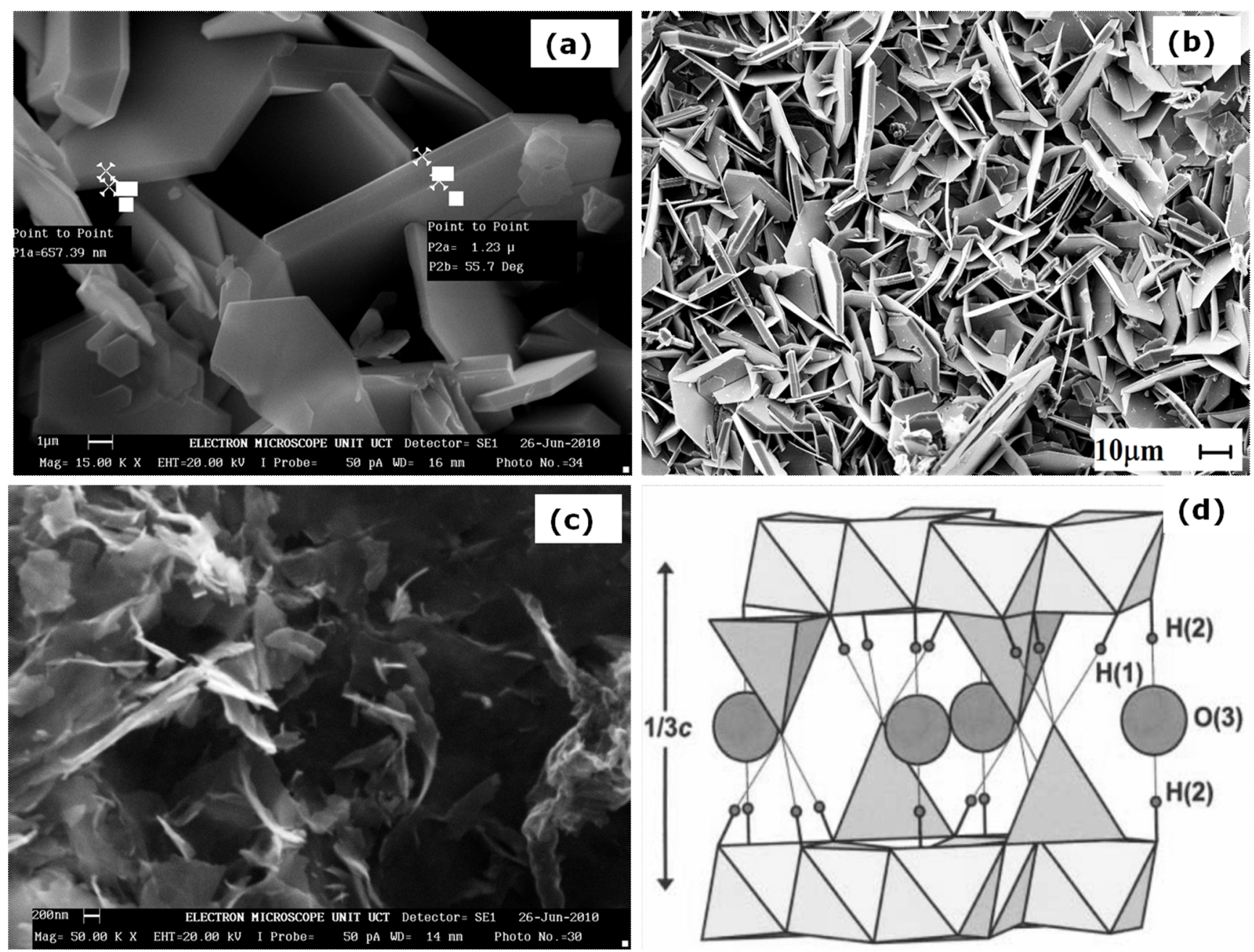

Figure 1 Typical scanning electron microscopy (SEM) images of the zinc hydroxychloride, $\mathrm{Zn}_{5}(\mathrm{OH})_{8} \mathrm{Cl}_{2} \cdot \mathrm{H}_{2} \mathrm{O}$ synthized for different conditions: (a) for $4 \mathrm{~h}$, (b) for $6 \mathrm{~h}$ and (c) for $24 \mathrm{~h}$; (d) Schematic model diagram of $2 \mathrm{D}$ growth mechanism. 


\section{Results and discussion}

Figs.1 (a \& b) depict representative scanning electron microscopy images of nano and micron scaled platelets. There is no net spatial orientation perpendicularly or parallel to the substrate wherever on pure glass or silicon substrates. The dense set of anisotropic nano/ micro platelets seem to grow faster along the basal plane and slower within the transversal direction. While their transversal size is within the nano-scaled range during the very early stage of the growth " 270 to $410 \mathrm{~nm}$ for $\sim 2 \mathrm{~h}$ deposition time", it increases reaching the micron range for higher deposition time " 2 to $10 \mu \mathrm{m}$ for $24 \mathrm{~h}$ ". As conveyed in Fig.1(c), it seems that the growth is more reinforced within the basal direction at the very early stages. One could observe that at such a stage, the particles are flakes type. This could imply a similar growth mechanism as for the ZnO nano/micro scaled rods synthesized by a similar hydrothermal procedure [5]. If so, the growth mechanism should be Frank-Van der Merwe driven process as well. Fig 1(d) depicts the schematic model diagram of 2D growth mechanism with the presence of $\mathrm{Cl}^{-}$ions (provided by the $\mathrm{NaCl}$ supporting electrolyte) detected throughout the 2D nanostructure capping the preferred [0001] facet and thereby redirecting growth in the (10ī0) plane forming the 2D micro/nano-structures under fast hydroxylation kinetics condition observed at a higher $\mathrm{Zn}\left(\mathrm{NO}_{3}\right)_{2} \cdot 6 \mathrm{H}_{2} \mathrm{O}$ electrolyte concentration. Indeed, as supported by the high resolution transmission electron microscopy image of Fig.2 (b), one can distinguish terraces like with quasi-sharp edges on the top of each other within the basal planes as indicated by the arrows. Consequentially, the growth mechanism is likely to be driven by a Frank-Van der Merwe. Fig.2 (a), a selected-area electron diffraction pattern, indicates the very high degree of crystallinity of the platelets with a net hexagonal symmetry and a possible crystallographic preferential orientation. This crystallinity indicates that the plate-like $\mathrm{Zn}_{5}(\mathrm{OH})_{8} \mathrm{Cl}_{2} \cdot \mathrm{H}_{2} \mathrm{O}$ possessed a smooth surface.

Such a significant crystallographic ordering is supported by the room temperature X-rays diffraction investigations. The characteristic XRD spectrum of the as-synthesized product is shown in Figure 3. The Rieveldt treatment and the identification of all Bragg diffraction peaks confirmed that the crystallographic phase of the nano/micro platelets is ascribed to pure rhombohedral simonkolleite (ICSD No. 07-0155) with lattice constants $\langle a\rangle$ and $<c>$ of about $\sim 6.337 \AA$ and $\sim 23.643 \AA$, respectively and space group R3m. The XRD analysis shows that all simonkolleite films have a strong preferential orientation along (003). The corresponding angular position of about $2 \Theta_{(003)} \sim 11.25$ is related to the highly ordered reticular planes characterized by an inter-reticular distance $\mathrm{d}_{003} \sim 7.881$. In view of the intensity of this (003) Bragg peak for all samples (inset Fig. 3), and as in the simonkolleite bulk crystals, one can conclude the lamellar structure of the synthesized simonkolleite nano/micro platelets too. This might be inferred that the high 


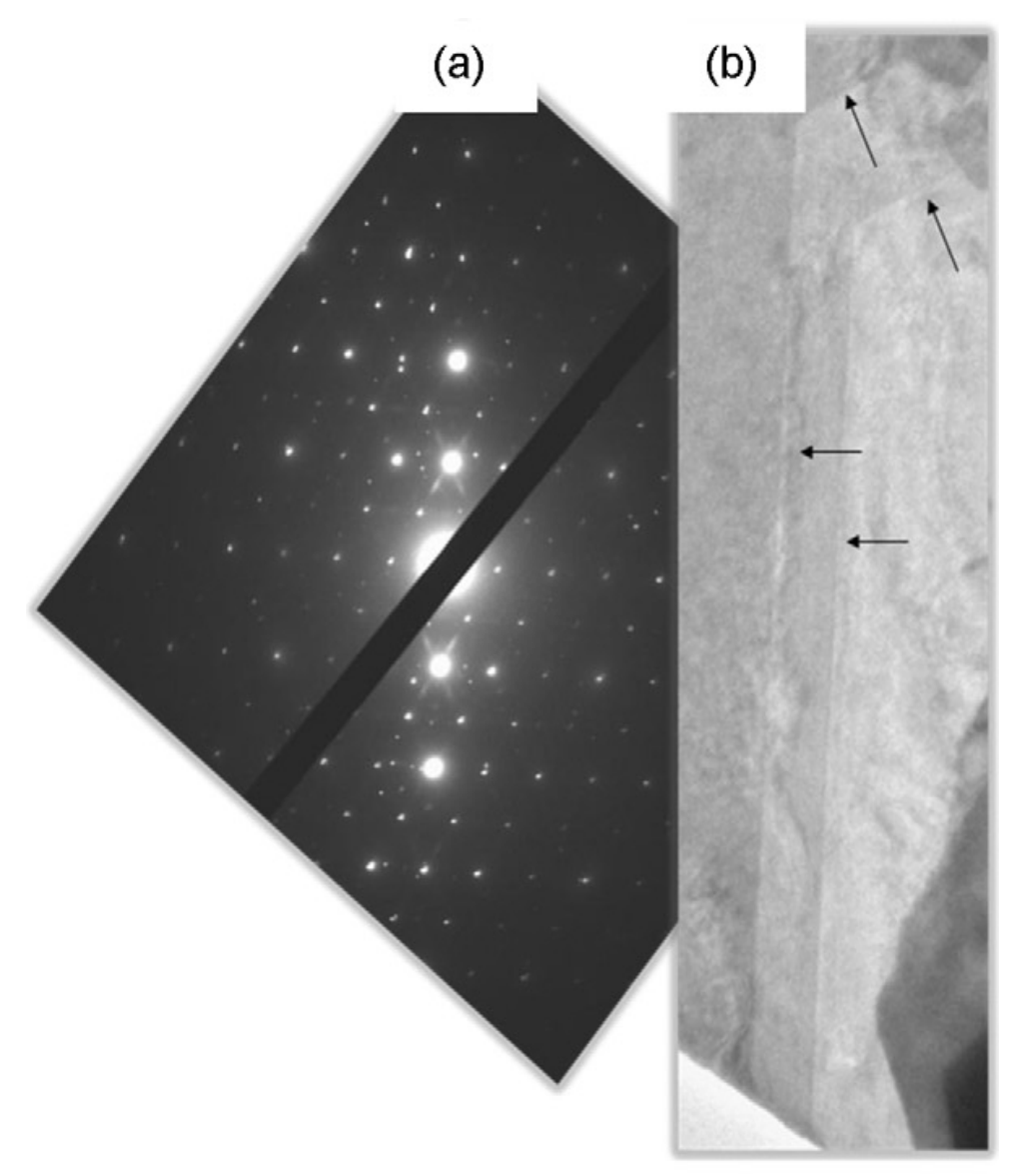

(c)

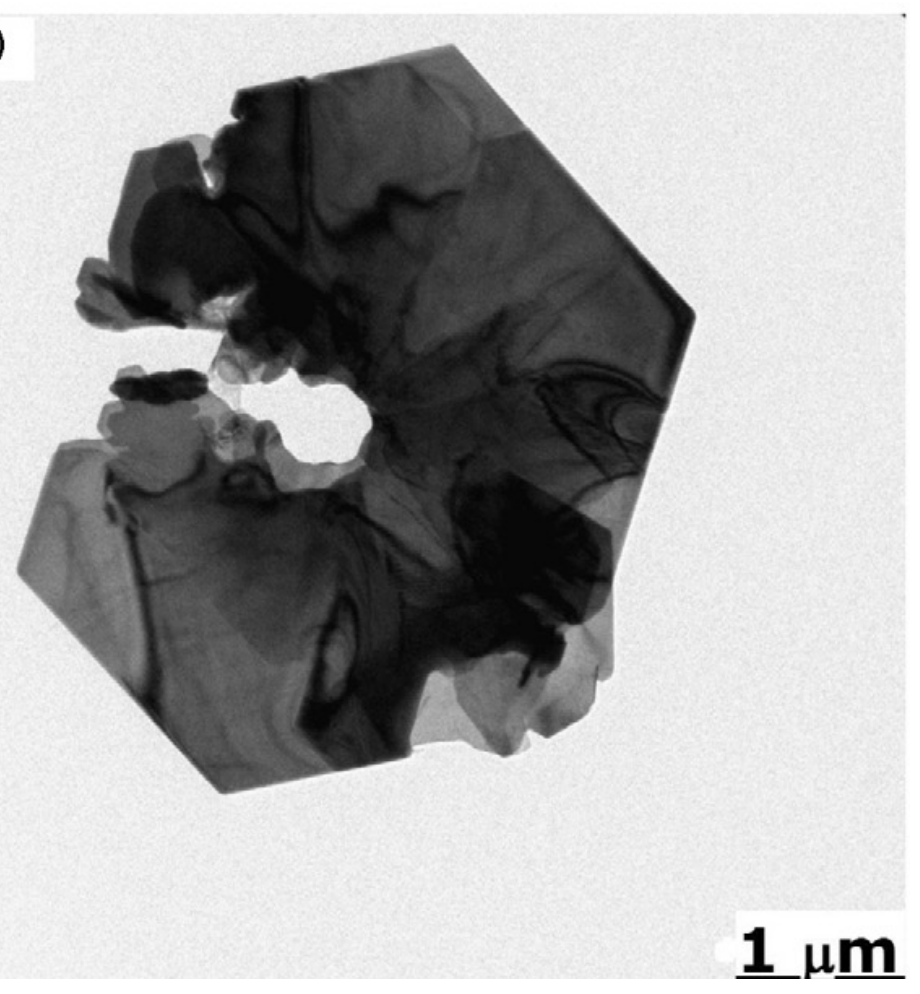

Figure 2 (a) selected-area electron diffraction pattern (SAED) of the zinc hydroxychloride, $\mathrm{Zn}_{5}(\mathrm{OH})_{8} \mathrm{Cl}_{2} \cdot \mathrm{H}_{2} \mathrm{O}$ plate-like structure, (b) typical high resolution transmission electron microscopy. 


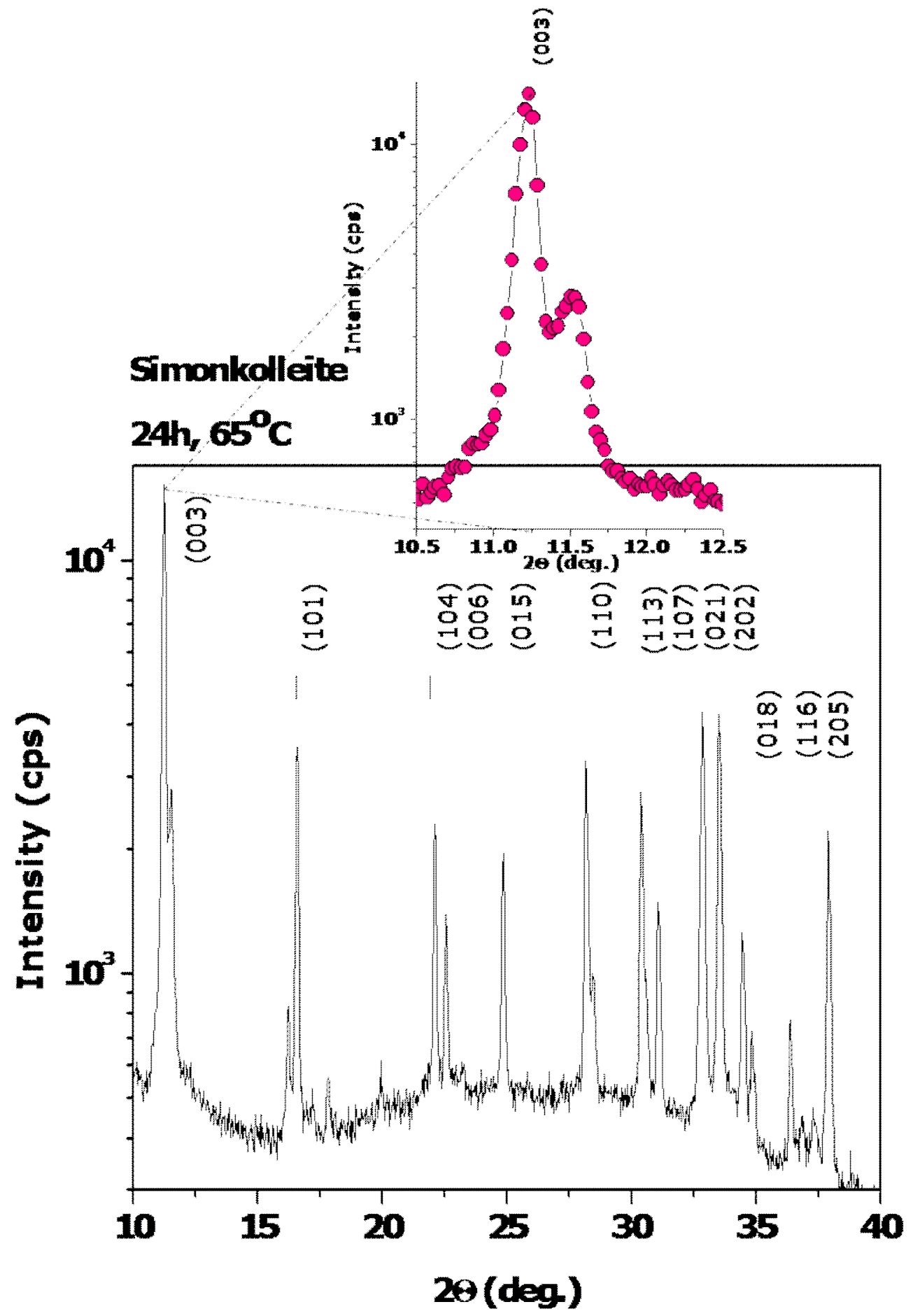

Figure 3 XRD spectrum of the as-synthesized zinc hydroxychloride, $\mathrm{Zn}_{5}(\mathrm{OH})_{8} \mathrm{Cl}_{2} \cdot \mathrm{H}_{2} \mathrm{O}$ plate-like structure. 
concentration of chloride ions favours the formation of the lamellar simonkolleite structure. The formation of $\mathrm{Zn}_{5}(\mathrm{OH})_{8} \mathrm{Cl}_{2} \cdot \mathrm{H}_{2} \mathrm{O}$ might proceed competitively in the solution following the successive chemical reactions:

$\begin{array}{ll}\cdot \mathrm{C}_{6} \mathrm{H}_{12} \mathrm{~N}_{4}+6 \mathrm{H}_{2} \mathrm{O} & \rightarrow \quad 6 \mathrm{HCHO}+4 \mathrm{NH}_{3} \\ \cdot \mathrm{NH}_{3}+\mathrm{H}_{2} \mathrm{O} \rightarrow & \mathrm{NH}^{4+}+\mathrm{OH}^{-} \\ \cdot \mathrm{NaCl} \quad \rightarrow & \mathrm{Na}^{+}+\mathrm{Cl}^{-} \\ \left.\cdot \mathrm{Zn}\left(\mathrm{NO}_{3}\right)_{2} \cdot 6 \mathrm{H}_{2}\right) & \rightarrow \quad \mathrm{Zn}^{2+}+\mathrm{NO}^{3-}+6 \mathrm{H}_{2} \mathrm{O}\end{array}$

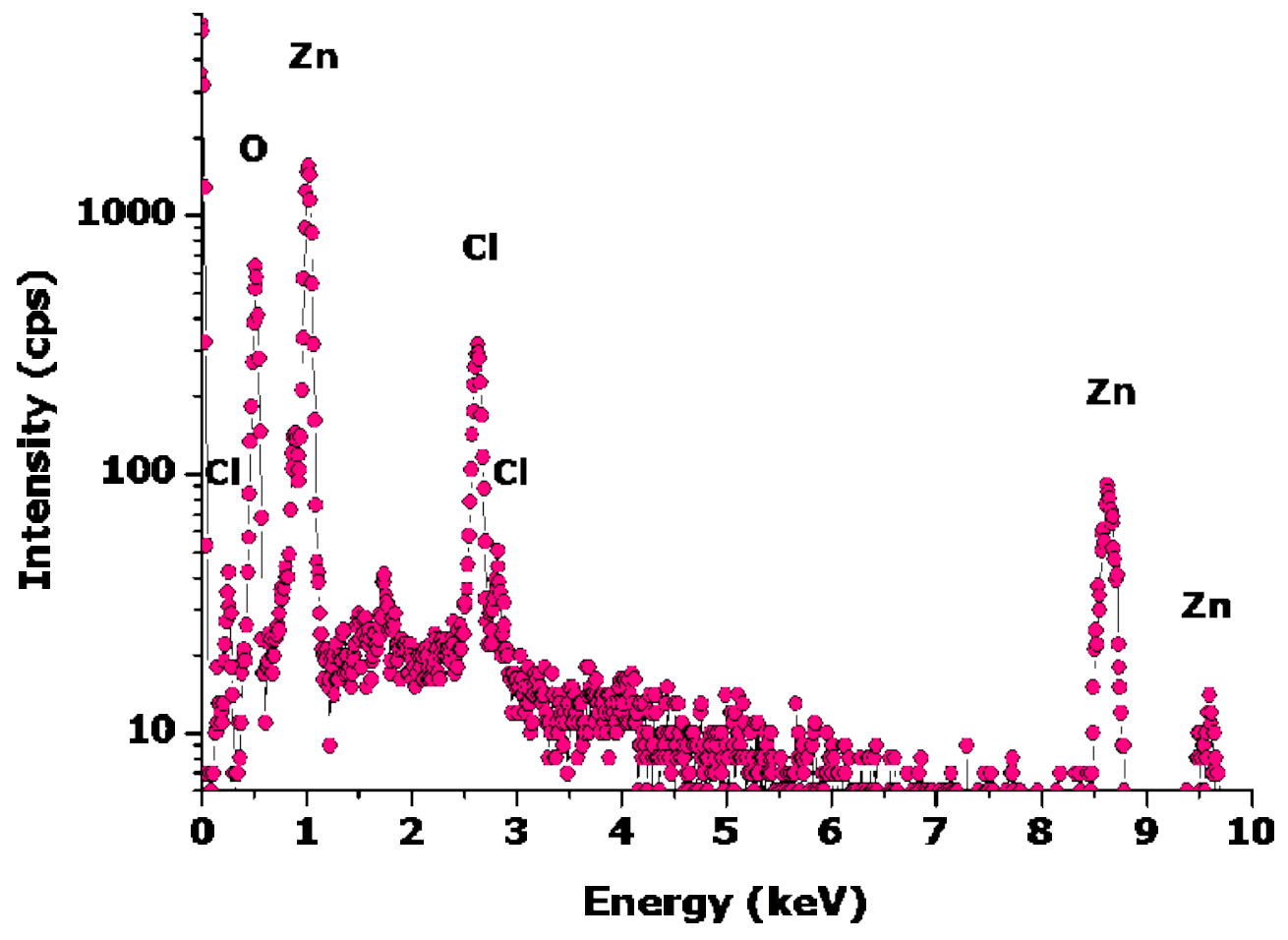

$\cdot 5 \mathrm{Zn}^{2+}+8 \mathrm{OH}^{-}+2 \mathrm{Cl}^{-}+\mathrm{H}_{2} \mathrm{O} \rightarrow \quad \mathrm{Zn}_{5}(\mathrm{OH})_{8} \mathrm{Cl}_{2} \cdot \mathrm{H}_{2} \mathrm{O}$

Figure 4 Electron dispersion $\mathrm{X}$-rays analysis of the zinc hydroxychloride, $\mathrm{Zn}_{5}(\mathrm{OH})_{8} \mathrm{Cl}_{2} \cdot \mathrm{H}_{2} \mathrm{O}$ plate-like structure.

The morphology of the final product changed greatly depending on $\mathrm{NaCl}$ additive. In the absence or less concentration of $\mathrm{NaCl}$, e.g. $0.001 \mathrm{M}$, the morphology was observed to be changing to a rod-like hexagonal structure. The electron dispersion $\mathrm{X}$-rays analysis (EDAX) data taken from the various samples indicate the presence of $\mathrm{Zn}, \mathrm{O}$ and $\mathrm{Cl}$ as illustrated in Figure 4. To concur again with both XRD and EDAX investigations on the purity of the simonkolleite nature of the nano/micron platelets, infrared attenuated total reflection (ATR) studies were performed. The ATR investigations were carried out in the 


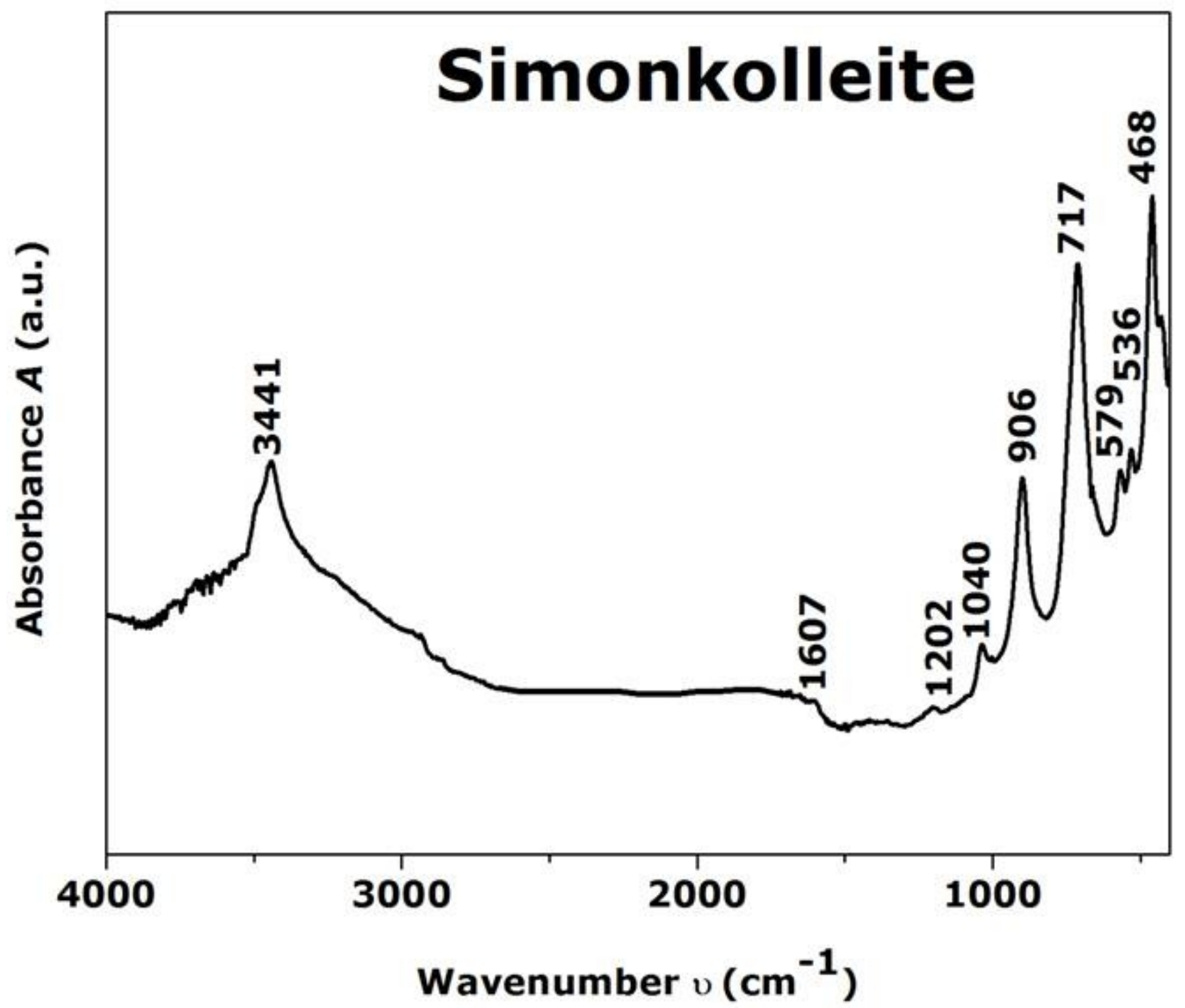

Figure 5 Typical infrared attenuated total reflection spectra of the prepared platelike $\mathrm{Zn}_{5}(\mathrm{OH})_{8} \mathrm{Cl}_{2} \cdot \mathrm{H}_{2} \mathrm{O}$ samples

spectral region of $4000-300 \mathrm{~cm}^{-1}$ focusing on $\mathrm{OH}$ stretches and $\mathrm{OH}$ librations as well as $\mathrm{Zn}-\mathrm{OH}$ modes proper to the simonkolleite at room temperature carried out on a Bruker model unit. Figure 5 reports a typical infrared attenuated total reflection spectra of the prepared plate-like $\mathrm{Zn}_{5}(\mathrm{OH})_{8} \mathrm{Cl}_{2} \cdot \mathrm{H}_{2} \mathrm{O}$ samples. Besides the strong band due to deformation vibration of $\mathrm{H}_{2} \mathrm{O}$ molecules at $1601 \mathrm{~cm}^{-1}$, and an absorption band centered at $3441 \mathrm{~cm}^{-1}$, characteristic of $\mathrm{O}-\mathrm{H}$ stretching vibration, specific bands at lower wavenumbers are observed. The bands are due to various stretching vibration modes of chloride ion [12-14]. More accurately, and according to the structural data, hydrogen bonds are formed between the $\mathrm{H}_{2} \mathrm{O}$ molecules ( $\mathrm{H}$ bond donors) and the $\mathrm{OH}$ groups $(\mathrm{H}$ 
bond acceptors) in $\mathrm{Zn}_{5}(\mathrm{OH})_{8} \mathrm{Cl}_{2} \cdot \mathrm{H}_{2} \mathrm{O}$. The hydrogen distances are reported to have values of 2.87 and $3.10 \AA$. The sharp bands on the higher frequency side of the spectrum "3588 and $3570 \mathrm{~cm}^{-1 "}$ are attributed to $\mathrm{V}_{\mathrm{OH}}$ of the two $\mathrm{OH}$ groups and those at 3495 and $3455 \mathrm{~cm}^{-1}$ to the stretch modes of $\mathrm{H}_{2} \mathrm{O}$. The bands at 906 and $717 \mathrm{~cm}^{-1}$ are assigned to $\mathrm{ZnOH}$ librations and those below $620 \mathrm{~cm}^{-1}$ to lattice modes. The bands in the region below $600 \mathrm{~cm}^{-1}$; i.e. at 569, 532, 457, 427 and $384 \mathrm{~cm}^{-1}$ are attributed to translational modes of the $\mathrm{Zn}-\mathrm{O}$ bonds.
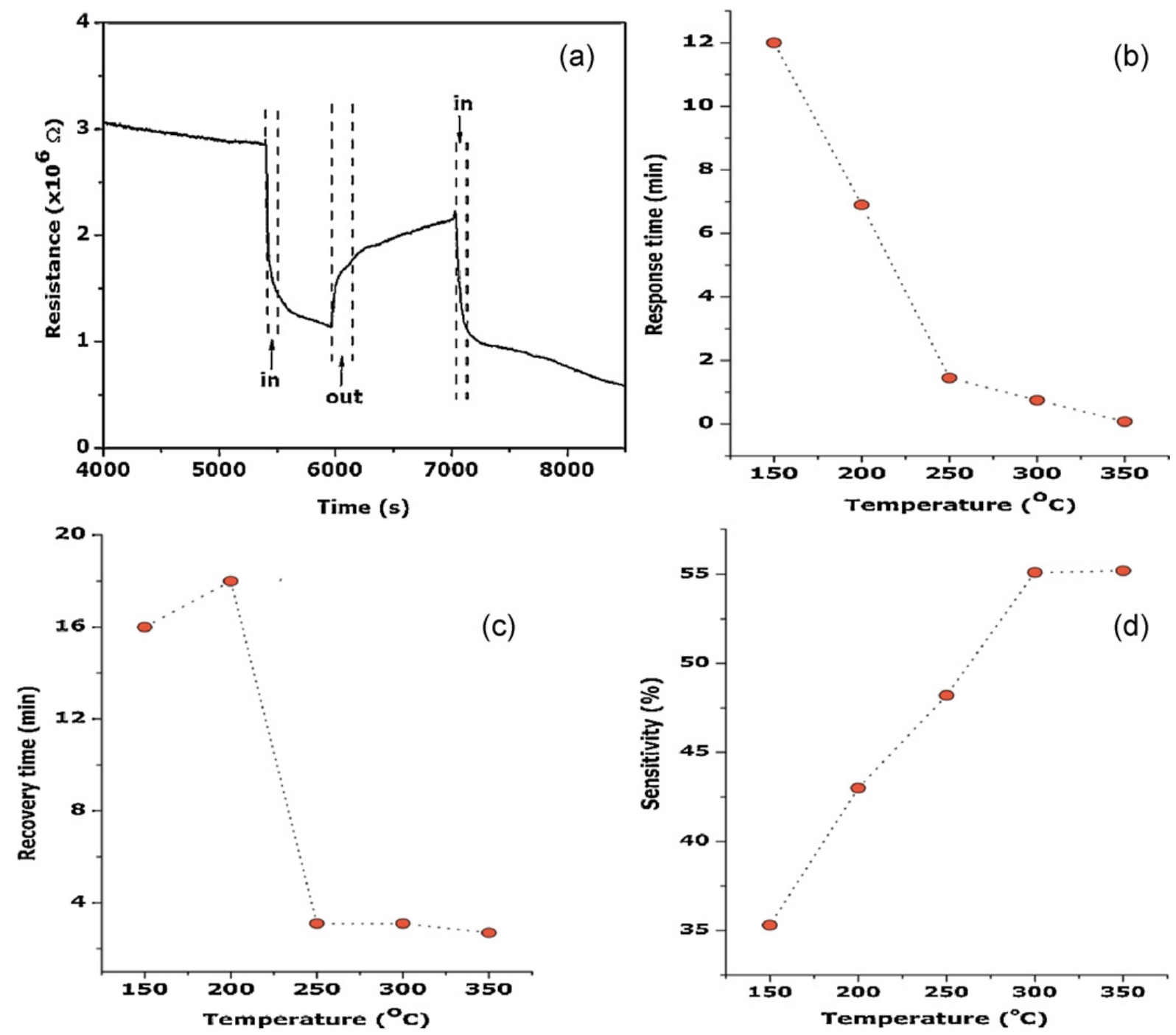

Figure 6 (a) the typical response of the sensor upon exposure to a gas concentration of $200 \mathrm{ppm} \mathrm{H}_{2}$ operated at $250{ }^{\circ} \mathrm{C}$; (b) the response time as a function of operating temperature; (c) the recovery time as a function of operating temperature and (d) sensitivity of the sample calculated and traced as a function of operating temperature

The $\mathrm{H}_{2}$ gas sensitivity $\mathrm{S}$ was determined by the relative resistance, $\left[\left(R_{\mathrm{air}}-R_{\mathrm{gas}}\right) / R_{\mathrm{air}}\right]$, where $R_{\text {air }}$ is the resistance of the sensor before passing the gas and $R_{\text {gas }}$ that after 
passing it. Systematic gas sensing studies were made on simonkolleite thin films, prepared at $85^{\circ} \mathrm{C}$, using $\mathrm{Cu}$ contacts. It is well known that the sensitivity is mainly determined by the dimensions of the microstructures. Figure 6(a) summarizes the typical responses of the sensor upon exposure to a gas concentration of $200 \mathrm{ppm} \mathrm{H}_{2}$ at $250{ }^{\circ} \mathrm{C}$ operating temperature. Crystallite size and the gas concentration are constant while the operating temperature is varied. The sensitivity of the sample is calculated and traced as a function of operating temperature as shown in Figure 6(d). The sensitivity increases with an increase with temperature until the saturation at $300^{\circ} \mathrm{C}$ (max. value of $67 \%$. Figure $6(\mathrm{~b})$ shows the response time as a function of operating temperature. The response time, similarly with the recovery time, decrease linearly with the increase in temperature until at $250{ }^{\circ} \mathrm{C}$. At $250^{\circ} \mathrm{C}$ and above, the response time and recovery time are 90 and 180s, respectively (Figure 6(b \& c)). These fast responses might be due to high polarity in plate-like structure of simonkolleite sample used at these high temperatures. As compared to $\mathrm{ZnO}$ with the response time and recovery time reported to be 200 and 800 s, respectively [14], our simonokolleite samples have lesser response and recovery time. Moreover, the sensitivity of the $50 \mathrm{~nm}$ diameter $\mathrm{ZnO}$ nanorod-arrays reaches the maximum value of $88 \%$ at $250^{\circ} \mathrm{C}$, which is around four times higher than the maximum sensitivity of the $500 \mathrm{~nm}$ diameter arrays achieved at $350^{\circ} \mathrm{C}$ [15]. Compared to our maximum sensitivity of simonkolleite in the range of (nano-micro)plates achieved at $300{ }^{\circ} \mathrm{C}$, simonkolleite sample is higher than the maximum sensitivity of the $500 \mathrm{~nm}$ diameter $\mathrm{ZnO}$ and comparable with the $50 \mathrm{~nm}$ diameter $\mathrm{ZnO}$ nanorodarrays. It is also several times higher than the sensitivity of ZnO films operated at temperatures from 300 to $400{ }^{\circ} \mathrm{C}$ [16]. The fast responses and high sensitivity might be due to high polarity and/or porosity in plate-like structure of simonkolleite samples.

\section{Conclusions}

The plate-like structure is strongly related to the formation of a simonkolleite processing layered structure. The growth habit might originate from hexagonal facet in nucleation, and subsequent layer growth mode (Frank-van der Merwe), along (003) plane. The molecular vibrational study of ATR data agreed with the crystalline structural XRD patterns and EDX shown that simonkolleite contained chloride ion. This crystallinity indicates that the plate-like $\mathrm{Zn}_{5}(\mathrm{OH})_{8} \mathrm{Cl}_{2} \cdot \mathrm{H}_{2} \mathrm{O}$ possessed a smooth surface. The lattice parameters and $d$-spacing values of (003) and (101) planes calculated, from X-ray diffraction data, correspond to the recorded values JCPDS, Card No. 007-0155. It might be inferred that the high concentration of zinc ion and chloride ion preferred to form simonkolleite plate-like structure. The sensitivity of the sample is calculated and traced as a function of operating temperature. The fast responses and high sensitivity might be due to high polarity and/or porosity in plate-like structure of simonkolleite sample used. 
The sensitivity $\Delta R / R$ of our sensor is attractive for further investigation for practical $\mathrm{H}_{2}$ sensor applications.

\section{Acknowledgment}

We wish to appreciate the financial support of the following institutions: the African Laser Centre "ALC"-Pretoria, the Abdus Salam ICTP-Trieste, the Nanosciences African Network "NANOAFNET"-Cape Town, iThemba LABS-National Research Foundation of South Africa and the French-South Africa as well as the Japan-South Africa bilateral cooperation programmes.

\section{References}

[1] H.T. Wang, B.S. Kang, F. Ren, L.C. Tien, P.W. Sadik, D.P. Norton, S.J. Pearton, J. Lin, Appl. Phys. Lett. 86(2005)243503

[2] L.C. Tien, P.W. Sadik, D.P. Norton, L.F. Voss, S.J. Pearton, H.T. Wang, B.S. Kang, F. Ren, J. Jun, J. Lin, Appl. Phys. Lett. 87(2005)222106

[3] B.S. Kang, Y.W. Heo, L.C. Tien, D.P. Norton, F. Ren, B.P. Gila, S.J. Pearton, Appl. Phys. A 80(2005)1029

[4] J.X. Wang, X.W. Sun, Y. Yang, H. Huang, Y.C. Lee, O.K. Tan, L. Vayssieres, Nanotechnology 17(2006)4995

[5] F. Favier, E.C. Walter, M.P. Zach, T. Benter, R.M. Penner, Science 293(2001)2227

[6] G.C. Yi, C. Wang, W. Park, Semicond. Sci. Technol. 20(2005)22

[7] L. Liao, H.B. Lu, J.C. Li, H. He, D.F. Wang, D.J. Fu, C. Liu, W.F. Zhang, J. Phys. Chem. 111(2007)1900

[8] H. Nanto; T. Minami, S. Takata J. Appl. Phys. 60(1986)482

[9] S. Roy, S. Basu, Bull. Mater. Sci., 25(2002)513

[10] F. Favier, E.C. Walter, M.P. Zach, T. Benter, R.M. Penner, Science 293(2001)2227

[11] G.C. Yi, C. Wang, W. Park, Semicond. Sci. Technol. 20(2005)22

[12] R. Allmann, Zeits. Krist. 126(1968)417

[13] F.C. Hawthorne and E. Sokolova, The Canadian Mineralogist, 40(2002)939

[14] T. Long, S. Yin, K. Takabatake, P. Zhang, and T. Sato, Nanoscale Res.Lett. 4 (2009)247

[15] L. Vayssieres and X.W. Sun, Sensor letters 6(2008)787

[16] Y. Min, H.L. Tuller, S. Pazer, J. Warren, J. Wollenstein, and H. Bottner, Sens. Actuotors, B 93(2003)435 